\title{
ROBUST DTC BASED ON ADAPTIVE FUZZY CONTROL OF DOUBLE STAR SYNCHRONOUS MACHINE DRIVE WITH FIXED SWITCHING FREQUENCY
}

\author{
Djamel Boudana — Lazhari Nezli — Abdelhalim Tlemçani \\ Mohand Oulhadj Mahmoudi - Mohamed Tadjine
}

\begin{abstract}
The double star synchronous machine (DSSM) is widely used for high power traction drives. It possesses several advantages over the conventional three phase machine. To reduce the torque ripple the DSSM are supplied with source voltage inverter (VSI). The model of the system DSSM-VSI is high order, multivariable and nonlinear. Further, big harmonic currents are generated. The aim of this paper is to develop a new direct torque adaptive fuzzy logic control in order to control DSSM and minimize the harmonics currents. Simulations results are given to show the effectiveness of our approach.
\end{abstract}

K e y w o r d s: double star synchronous machine (DSSM), direct torque control (DTC), tree level inverter, fixed switching frequency adaptive fuzzy control, harmonic currents

\section{INTRODUCTION}

Synchronous machines are attractive for high powers. When they are supplied by thyristors current source inverter (CSI) torque oscillations of high amplitude at six times the supply frequency appear $[1,2]$. This causes excess mechanical vibration and poor system performance. The use of two star windings shifted by $30^{\circ}$ supplied by two thee phase voltage source inverters (VSIs) lowers considerably the torque ripple $[3,4]$. However, the model of the system DSSM-VSIs in Park frame is high order, multivariable and non linear

Direct torque control is a very simple method to control AC machines. It shows a very high quality torque control without the need of tuning current controllers. The principle of conventional DTC consists to select stator voltage vectors, according to the differences between the stator flux linkage and torque and their references, to keep stator flux and torque within the limits of two hysteresis bands. However, the disadvantages of conventional DTC include notable torque, flux and current pulsations and non-constant switching frequency operation $[5,6]$.

The advantages allotted to traditional techniques DTC (dynamic, robustness, facilitated implementation ... ) nevertheless are counterbalanced by the use of a sampled hysteresis comparator; by principle, the comparator led functioning at variable frequency which increases the risks of mechanical excitation or acoustic resonances, and in addition, sampling at finished frequency results by an exceeding pseudo-random of the hysteresis band. These two factors contribute to make the contents harmonic of the various output signals not easily foreseeable.

Alternatively, space vector modulation (SVM) modulator is incorporated with direct torque control for induction motor drives and permanent magnet synchronous motors as shown in [7-9] to provide a constant inverter switching frequency. Noting that the torque ripple and noise issue for this SVM-based DTC approach are significantly improved for invoking zero inverter switching state within every switching period of inverter control.

Recently, there has been an increasing interest in adaptive fuzzy control (AFC) for non-linear dynamic systems. This interest has been motivated by the demands for high control performance in situations in which an accurate model of the controlled plant is not easily available, or when the plant undergoes unforeseen parameter variations. Fuzzy systems have the potential to play an important role in adaptive control, mainly thanks to their universal function approximation property and their amenability to (linguistic) interpretation of the inputoutput relationships.

An adaptive fuzzy controller is expected to comply with the following design requirements: (i) stability of the closed-loop system (all signals in the closed-loop must be bounded), (ii) asymptotic convergence of the tracking error to zero or to a neighbourhood of zero, (iii) robustness with respect to the approximation error, unavoidably introduced by any approximator with a finite number of parameters. The approximation error is usually treated as a disturbance acting on the system by means of standard modifications: an additional non-linear damping term, usually in a sliding mode framework [10-12].

The aim of this article is to develop an adaptive fuzzy control of DTC double star synchronous machine drive with fixed switching frequency. The fuzzy systems are used to approximate the model of controlled system. In order to compensate for the effects of the unavoidable reconstruction errors, we introduce a sliding term into the control law. The approximation theory and the Lyapunov method are used together to construct, in the first stage, the fuzzy adaptive control law and to establish, in the second stage, the convergence of the tracking error

* LCP, ENP, 10 av. Pasteur, Hassen Badi, 16200 El Harrach, Alger, Algeria, mohamed.tadjine@mail.enp.edu.dz 
and the boundedness of the adaptive parameters and all plant signals. Furthermore, the space vector modulation technique is applied to inverter control in the proposed DTC-based double star synchronous motor drive system, thereby dramatically reducing the torque ripple, current harmonic and to impose the switching frequency.

The remainder of this paper is structured as follows: in Section 2 the used fuzzy logic system is briefly described and Section 3 is devoted to the problem statement. The machine model is developed in Section 4. In Section 5, the direct torque control of DSSM of double star synchronous machine drive is presented. The DTC adaptive fuzzy control is developed in Section 6. Finally, the conclusions are presented in Section 7.

\section{DESCRIPTION OF THE USED FUZZY LOGIC SYSTEM}

The fuzzy logic system performs a mapping from $U_{1} \times$ $\cdots \times U_{n} \subset R^{n}$ to $R$ where each $U_{i} \subset R, i=1,2, \ldots, n$. For the proposed fuzzy logic system, we use the implication and the reasoning method suggested by Takagi and Sugeno [13]. Consequently, the fuzzy IF-THEN rules are expressed as

$$
R_{k}: \text { if } x_{1} \text { is } A_{1}^{l 1} \text { and } \ldots x_{n} \text { is } A_{n}^{l n} \text { then } z_{k}=a^{k}
$$

where $x=\left[\begin{array}{llll}x_{1} & x_{2} & \ldots & x_{n}\end{array}\right]^{\top} \in \Re^{n}$ and $z_{k} \in \Re$ are respectively the input of the fuzzy logic system and the consequent of the $k^{\text {th }}$ rule. Here, the label $A_{i}^{l i}$ associated to input $x_{i}(i=1, \ldots, n)$ is a fuzzy set in $U_{i}$ where the indices $l i$ takes a value in $\left\{1, \ldots, m_{i}\right\}$ and $m_{i}$ is the number of fuzzy sets characterising the input $x_{i}$. The coefficient $a^{k}$ ( for $k=1,2, \ldots, M$ ) is a constant coefficient of consequent part for the $k^{\text {th }}$ fuzzy rule. The number of rules $M$ is defined by the cartesian product as: $M=m_{1} \otimes m_{2} \otimes \cdots \otimes m_{n}$.

In this paper, we employ the product operation for fuzzy implication and $T$-norm. The definition of the product operation is the same as in [14]. Besides, the singleton fuzzifier and weighted average deffuzzification is used. The overall output value $z(x)$ is

$$
z(x)=\frac{\sum_{k=1}^{M} \alpha_{k} a^{k}}{\sum_{k=1}^{M} \alpha_{k}}
$$

Where $\alpha_{k}$ denotes the firing strength of the $R_{k}$ rule, which is evaluated by using product inference and implication as

$$
\alpha_{k}=\prod_{i=1}^{n} \mu A_{i}^{l i}\left(x_{i}\right) ; \quad \text { with } l_{i} \in\left\{1, \ldots, m_{i}\right\}
$$

where $\mu A_{i}^{l i}\left(x_{i}\right)$ is the membership function of $x_{i}$ associated to fuzzy set $A_{i}^{l i}$.

In (2), we fix the $\mu A_{i}^{l i}\left(x_{i}\right) \mathrm{s}$ and $a^{k} \mathrm{~s}$ form the adjustable parameters, $z(x)$ can be rewritten as

$$
z(x)=w^{\top}(x) \theta
$$

where $\theta$ is the parameter vector given by

$$
\theta=\left[a^{1} a^{2} \ldots a^{M}\right]^{\top}
$$

and $w^{\top}(x)$ is a regressive vector defined as

$$
w^{\top}(x)=\left[\begin{array}{llll}
\frac{\alpha_{1}}{\sum_{k=1}^{M} \alpha_{k}} & \frac{\alpha_{2}}{\sum_{k=1}^{M} \alpha_{k}} & \cdots & \frac{\alpha_{M}}{\sum_{k=1}^{M} \alpha_{k}}
\end{array}\right]
$$

In the sequel, the fuzzy logic system for multi-input single output system is represented by the mathematical model (4).

\section{PROBLEM FORMULATION}

The control of the DSSM supplied by voltage source inverters (VSIs) is very difficult since the model of the machine is high order, multivariable and non linear. Figure 1 presents the decoupled control scheme for DSSM supplied by two three level inverters. The decoupled control bloc is based on DTC control strategy witch the stator flux linkage and the torque would be decoupled.

\section{MACHINE MODEL}

In developing the equations which describe the behaviour of DSSM, the following assumptions are made:

- The MMF in air-gap has a sinusoidal repartition.

- The saturation of the iron in machine is neglected.

The stator voltage equation for six-phase can be written as

$$
\begin{gathered}
\boldsymbol{v}_{s}=\mathbf{R}_{s} \mathbf{i}_{s}+\frac{\mathrm{d}}{\mathrm{d} t}\left(\mathbf{L}_{s s} \mathbf{i}_{s}+\mathbf{M}_{s r} i_{f}\right) \\
\mathbf{v}_{s}=\left[\begin{array}{llllll}
v_{a 1} & v_{a 2} & v_{b 1} & v_{b 2} & v_{c 1} & v_{c 2}
\end{array}\right]^{\top}, \\
\boldsymbol{i}_{s}=\left[\begin{array}{llllll}
i_{a 1} & i_{a 2} & i_{b 1} & i_{b 2} & i_{c 1} & i_{c 2}
\end{array}\right]^{\top} .
\end{gathered}
$$

The original six dimensional system of the machine can be decomposed into three orthogonal subspaces $(\alpha, \beta)$, $\left(Z_{1}, Z_{2}\right)$ and $\left(Z_{3}, Z_{4}\right)[15,18]$

$$
\left[\begin{array}{llllll}
F_{\alpha} & F_{\beta} & F_{z 1} & F_{z 2} & F_{z 3} & F_{z 4}
\end{array}\right]^{\top}=\mathbf{T}_{s} \mathbf{F}_{s}
$$

with $F$ : can be voltage, current or flux.

$\mathbf{T}_{s}=\frac{1}{\sqrt{3}} \times$

$\left(\begin{array}{cccccc}\cos 0 & \cos \gamma & \cos \frac{2 \pi}{3} & \cos \left(\frac{2 \pi}{3}+\gamma\right) & \cos \frac{4 \pi}{3} & \cos \left(\frac{4 \pi}{3}+\gamma\right) \\ \sin 0 & \sin \gamma & \sin \frac{2 \pi}{3} & \sin \left(\frac{2 \pi}{3}+\gamma\right) & \sin \frac{4 \pi}{3} & \sin \left(\frac{4 \pi}{3}+\gamma\right) \\ \cos 0 & \cos (\pi-\gamma) & \cos \frac{4 \pi}{3} & \cos \left(\frac{\pi}{3}-\gamma\right) & \cos \frac{2 \pi}{3} & \cos \left(\frac{5 \pi}{3}-\gamma\right) \\ \sin 0 & \sin (\pi-\gamma) & \sin \frac{4 \pi}{3} & \sin \left(\frac{\pi}{3}-\gamma\right) & \sin \frac{2 \pi}{3} & \sin \left(\frac{5 \pi}{3}-\gamma\right) \\ 1 & 0 & 1 & 0 & 1 & 0 \\ 0 & 1 & 0 & 1 & 0 & 1\end{array}\right)$ 


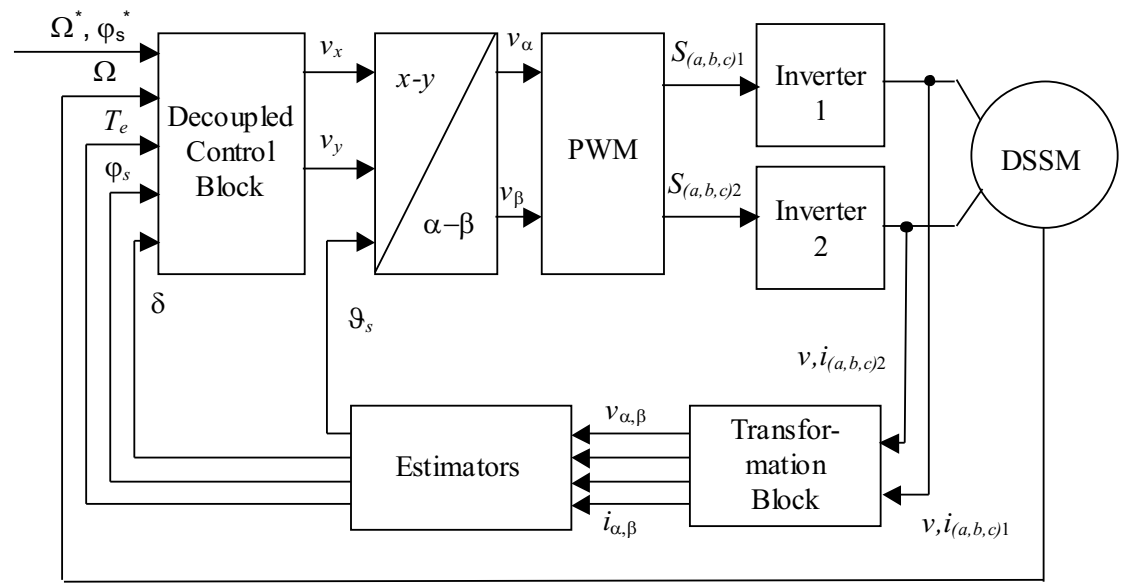

Fig. 1. Decoupled control scheme for DSSM

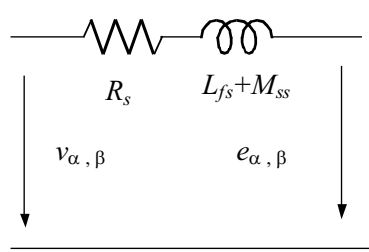

(a)

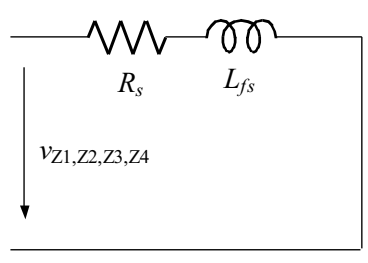

(b)
Fig. 2. Equivalent circuit of the DSSM model in: (a) $-\alpha-\beta$ subspace, (b) $-Z_{1}, Z_{2}$ and $Z_{3}, Z_{4}$ subspaces

\subsection{Machine model in $\alpha-\beta$ subspace}

The stator voltage equation is

$$
\begin{gathered}
\left(\begin{array}{c}
v_{\alpha} \\
v_{\beta}
\end{array}\right)=R_{s}\left(\begin{array}{l}
i_{\alpha} \\
i_{\beta}
\end{array}\right)+\frac{\mathrm{d}}{\mathrm{d} t}\left(\begin{array}{cc}
l_{f s}+3 M_{s s} & 0 \\
0 & l_{f s}+3 M_{s s}
\end{array}\right)\left(\begin{array}{c}
i_{\alpha} \\
i_{\beta}
\end{array}\right) \\
+\sqrt{3} M_{s f} \frac{\mathrm{d}}{\mathrm{d} t}\left(\begin{array}{c}
\cos (\theta) \\
\sin (\theta)
\end{array}\right) i_{f} \\
+M_{s f m} \frac{\mathrm{d}}{\mathrm{d} t}\left(\begin{array}{cc}
3 \cos (2 \theta) & 3 \sin (2 \theta) \\
3 \sin (2 \theta) & -3 \cos (2 \theta)
\end{array}\right)\left(\begin{array}{c}
i_{\alpha} \\
i_{\beta}
\end{array}\right) .
\end{gathered}
$$

An equivalent circuit of DSSM in $\alpha$ - $\beta$ subspace is shown in Fig. 2a.

\subsection{Machine model in $Z_{1}, Z_{2}$ subspace}

The stator voltage equation is

$$
\left(\begin{array}{c}
v_{z 1} \\
v_{z 2}
\end{array}\right)=R_{s}\left(\begin{array}{c}
i_{z 1} \\
i_{z 2}
\end{array}\right)+\frac{\mathrm{d}}{\mathrm{d} t}\left(\begin{array}{cc}
l_{f s} & 0 \\
0 & l_{f s}
\end{array}\right)\left(\begin{array}{l}
i_{z 1} \\
i_{z 2}
\end{array}\right) .
$$

The currents harmonics $i_{z 1}$ and $i_{z 2}$ must be as low as possible to reduce the extra losses in the DSSM. These currents are only limited by stator resistance and leakage inductance. An equivalent circuit of DSSM in $Z_{1}, Z_{2}$ subspace is shown in Fig. 2 b.

\subsection{Machine model in $Z_{3}, Z_{4}$ subspace}

The stator voltage equation is

$$
\left(\begin{array}{c}
v_{z 3} \\
v_{z 4}
\end{array}\right)=R_{s}\left(\begin{array}{c}
i_{z 3} \\
i_{z 4}
\end{array}\right)+\frac{\mathrm{d}}{\mathrm{d} t}\left(\begin{array}{cc}
l_{f s} & 0 \\
0 & l_{f s}
\end{array}\right)\left(\begin{array}{l}
i_{z 3} \\
i_{z 4}
\end{array}\right) .
$$

The currents $i_{z 3}$ and $i_{z 4}$ are equal to zero because the two three-phase windings are connected with isolated neutrals.

\subsection{Machine model in rotor reference frame $d-q$}

To express the stator and rotor equations in the same stationary reference frame, the following rotation transformation is appropriate

$$
\mathbf{P}=\left(\begin{array}{cc}
\cos \theta & -\sin \theta \\
\sin \theta & \cos \theta
\end{array}\right)
$$

With this transformation, the components of the $\alpha-\beta$ plane can be expressed in the $d-q$ plane as

$$
\left(\begin{array}{l}
v_{d} \\
v_{q}
\end{array}\right)=\left(\begin{array}{cc}
R_{s}+p L_{d} & -\omega L_{d} \\
\omega L_{d} & R_{s}+p L_{d}
\end{array}\right)\left(\begin{array}{c}
i_{d} \\
i_{q}
\end{array}\right)+M_{d} \omega\left(\begin{array}{l}
0 \\
1
\end{array}\right) i_{f} .
$$

The electromagnetic torque of DSSM is expressed as

$$
T_{e}=P\left(\phi_{d} i_{q}-\phi_{q} i_{d}\right) \text {. }
$$

\subsection{Machine model in stator flux reference} frame $x-y$

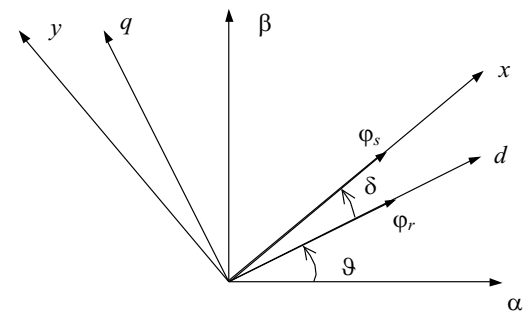

Fig. 3. The stator and rotor flux linkages in different reference frames

In order to control directly and independently the flux and the torque the model of the DSSM is expressed in the stator flux reference frame by using the following transformation, witch transforms variable in the rotor flux reference frame $(d-q)$ to the stator flux reference frame $x-y$ (Fig. 3)

$$
\left(\begin{array}{cc}
\cos \delta & \sin \delta \\
-\sin \delta & \cos \delta
\end{array}\right)
$$

The stator flux linkage and electromagnetic torque equations in $x-y$ reference frame are as follows

$$
\begin{aligned}
& v_{x}=R_{s} i_{x}-w_{s} L_{d} i_{y}+L_{d} \frac{\mathrm{d} i_{x}}{\mathrm{~d} t}+w \phi_{r} \sin \delta, \\
& v_{y}=R_{s} i_{y}+w_{s} L_{d} i_{x}+L_{d} \frac{\mathrm{d} i_{y}}{\mathrm{~d} t}+w \phi_{r} \cos \delta
\end{aligned}
$$




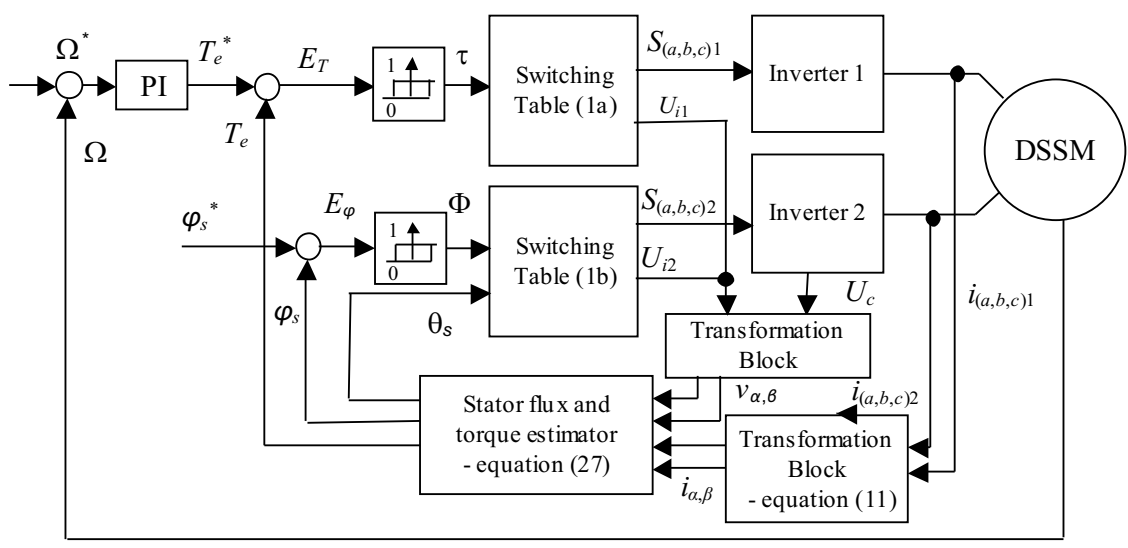

Fig. 4. Direct torque control scheme for DSSM

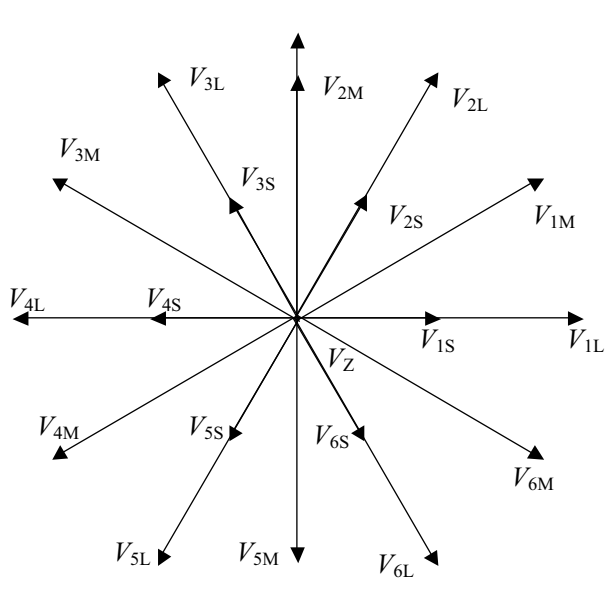

Fig. 5. Voltage vectors of three-level

$w_{s}$ : rotating speed of stator flux linkage

$\delta$ : Angle between rotor and stator flux linkage.

The fluxes and the torque are given by

$\phi_{x}=\phi_{s}=L_{d} i_{x}+\phi_{r} \cos \delta, \quad \phi_{y}=0=L_{d} i_{y}-\phi_{r} \sin \delta$,

$$
T_{e}=P \phi_{s} i_{y}
$$

From (13) and (14) the model for the DSSM can be written like:

$$
\frac{\mathrm{d} \phi_{s}}{\mathrm{~d} t}=f_{1}+b_{1} v_{x}, \frac{\mathrm{d} T_{e}}{\mathrm{~d} t}=f_{2}+b_{2} v_{y}, \frac{\mathrm{d} \Omega}{\mathrm{d} t}=f_{3}+b_{3} T_{e}
$$

$f_{1}=-\frac{R_{s}}{L_{d}}\left(\phi_{s}-\phi_{r} \cos \delta\right)$,

$f_{2}=-\frac{P \phi_{s}}{L_{d}}\left(R_{s} i_{y}+w_{s} \phi_{s}+\left(w_{s}-w\right) \phi_{r} \cos \delta\right)-P i_{y} \dot{\phi}_{s}$,

$f_{3}=-\frac{1}{j}\left(T_{r}+f_{c} \Omega\right)$,

$b_{1}=1, \quad b_{2}=\frac{P \phi_{s}}{L_{d}}, \quad b_{3}=\frac{1}{j}$.

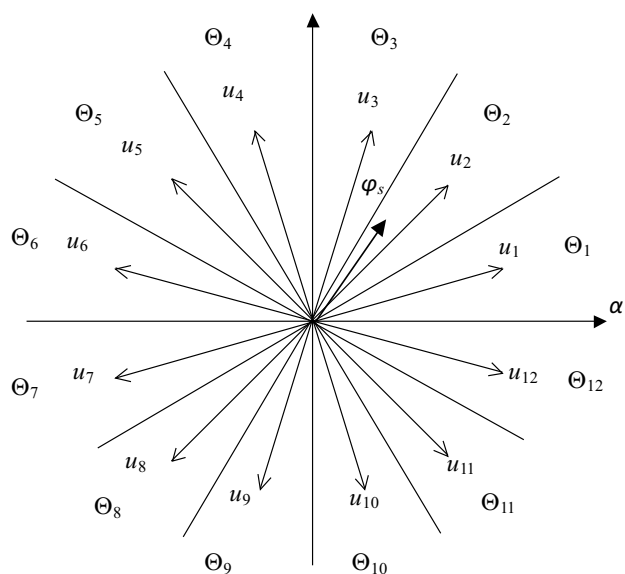

Fig. 6. The chosen inverter voltage vectors projected on $\alpha-\beta$ plane

\section{DIRECT TORQUE CONTROL OF DSSM}

The basic principle of the DTC is to select proper voltage vectors using a pre-defined switching table. The selection is based on the hysteresis control of the stator flux linkage and the torque [16] [17]. The principle of DTC control is based on the space vector notation. The space vectors of the voltage, current and flux of the DSSM are defined as follows

$$
\begin{gathered}
\bar{v}_{s}=\sqrt{\frac{2}{3}}\left(v_{a 1}+v_{b 1} e^{j \frac{2 \pi}{3}}+v_{c 1} e^{j \frac{4 \pi}{3}}+v_{a 2} e^{j \gamma}+\right. \\
\left.v_{b 2} e^{j\left(\frac{2 \pi}{3}+\gamma\right)}+v_{c 2} e^{j\left(\frac{4 \pi}{3}+\gamma\right)}\right) \\
\bar{i}_{s}=\sqrt{\frac{2}{3}\left(i_{a 1}+i_{b 1} e^{j \frac{2 \pi}{3}}+i_{c 1} e^{j \frac{4 \pi}{3}}+i_{a 2} e^{j \gamma}+\right.} \\
\left.i_{b 2} e^{j\left(\frac{2 \pi}{3}+\gamma\right)}+i_{c 2} e^{j\left(\frac{4 \pi}{3}+\gamma\right)}\right) \\
\bar{\phi}_{s}=\sqrt{\frac{2}{3}}\left(\phi_{a 1}+\phi_{b 1} e^{j \frac{2 \pi}{3}}+\phi_{c 1} e^{j \frac{4 \pi}{3}}+\phi_{a 2} e^{j \gamma}+\right. \\
\left.\phi_{b 2} e^{j\left(\frac{2 \pi}{3}+\gamma\right)}+\phi_{c 2} e^{j\left(\frac{4 \pi}{3}+\gamma\right)}\right) .
\end{gathered}
$$

Neglecting the stator resistance, the relation between the stator flux linkage vector and the voltage vector of DSSM 


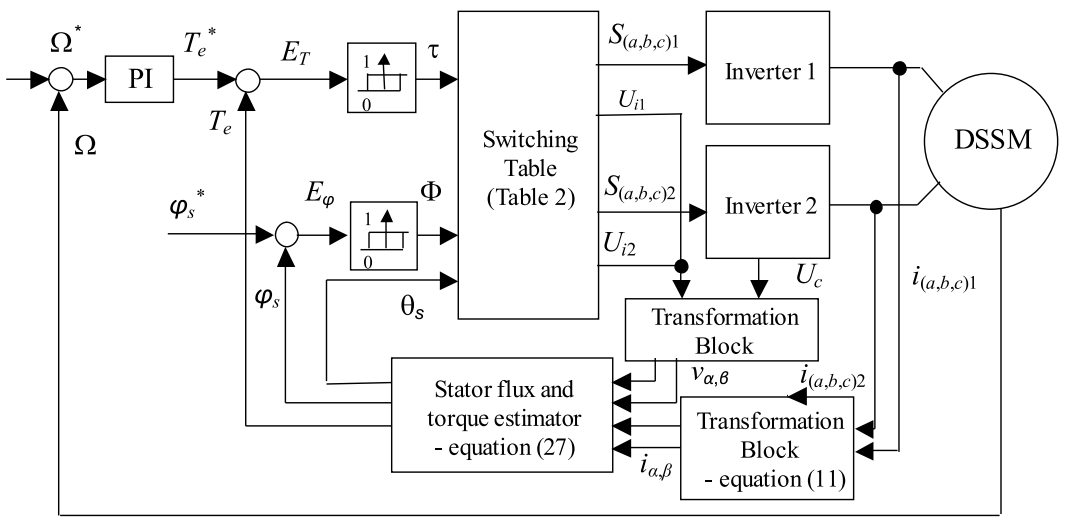

Fig. 7. Direct torque control scheme for DSSM when $\Omega<\Omega_{\text {nom }} / 2$

Table 1. The switching states for inverters when $\Omega \geq \Omega_{\text {nom }} / 2$

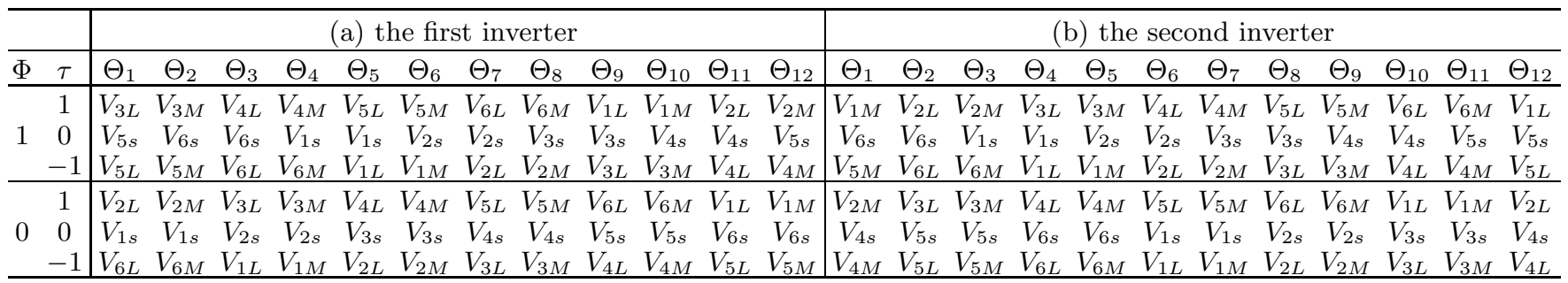

can be approximated by

$$
\bar{\phi}_{s}\left(T_{s}\right) \approx \bar{v}_{s} T_{s}+\bar{\phi}_{s}(0)
$$

Replacing the voltage vector (17) in (18) the flux linkage vector can be written as

$$
\begin{gathered}
\bar{\phi}_{s}\left(T_{s}\right) \approx \bar{v}_{s 1} T_{s}+\bar{v}_{s 2} T_{s}+\bar{\phi}_{s}(0) \\
\bar{v}_{s 1}=\sqrt{\frac{2}{3}}\left(v_{a 1}+v_{b 1} e^{j \frac{2 \pi}{3}}+v_{c 1} e^{j \frac{4 \pi}{3}}\right), \\
\bar{v}_{s 2}=\sqrt{\frac{2}{3}}\left(v_{a 2} e^{j \gamma}+v_{b 2} e^{j\left(\frac{2 \pi}{3}+\gamma\right)}+v_{c 2} e^{j\left(\frac{4 \pi}{3}+\gamma\right)}\right) .
\end{gathered}
$$

It can be seen from equation (25) that the stator flux linkage can be controlled by application of the output voltages vectors of each inverter independently. Figure 4 shows the proposed DTC scheme for DSSM.

The stator flux linkage and the torque are estimated with

$$
\begin{aligned}
\phi_{\alpha}(t) & =\int_{0}^{t}\left(v_{\alpha}-R_{s} i_{\alpha}\right) \mathrm{d} \tau+\phi_{\alpha}(0), \\
\phi_{\beta}(t) & =\int_{0}^{t}\left(v_{\beta}-R_{s} i_{\beta}\right) \mathrm{d} \tau+\phi_{\beta}(0), \\
\phi_{s} & =\frac{1}{\sqrt{3}} \sqrt{\phi_{\alpha}^{2}+\phi_{\beta}^{2}}, \\
\operatorname{tg} \theta_{s} & =\frac{\phi_{\beta}(t)}{\phi_{\alpha}(t)}, \\
T_{e} & =P\left(\phi_{\alpha} i_{\beta}-\phi_{\beta} i_{\alpha}\right) .
\end{aligned}
$$

\subsection{Selection of voltage vectors}

The DSSM is supplied by two three-level VSIs. Each inverter can be controlled independently. Three-level inverter has 27 vectors, which has 8 redundant vectors in it. Figure 5 shows the voltage vectors of the first threelevel inverter in $\alpha-\beta$ frame, in which subscripts $Z, S, M$, and $L$ denote zero, small, medium, and large voltages, respectively.

In order to minimize the torque and flux ripple in low speed, only the small voltage vector is applied when speed $\Omega<\Omega_{\text {nom }} / 2$. In this case the three-level inverter is similar to the two-level inverter. However if we consider the two inverters as a six-phase voltage source inverter we obtain a total of 64 switching modes. By using the transformation matrix (5) the 64 voltage vectors corresponding to the switching modes are projected on three planes. From 64 vectors there are only 12 voltage vectors that offer a maximum voltage on the $\alpha-\beta$ plane and keep the harmonics on the $Z_{1} Z_{2}$ plane at a minimum [18].

The voltage vector plane is divided into twelve sectors so that each voltage vector divides each region into two equal parts as shown in Fig. 6. In each sector, four of the twelve voltage vectors may be used $[19,20]$. The used control system is depicted in Fig. 7.

The switching table used is indicated in Table 2. The output of the flux hysteresis comparator is denoted as $\Phi$, the output of the torque hysteresis comparator is denoted as $\tau$. The flux hysteresis comparator is a two valued comparator and the torque hysteresis comparator is a three valued comparator. 

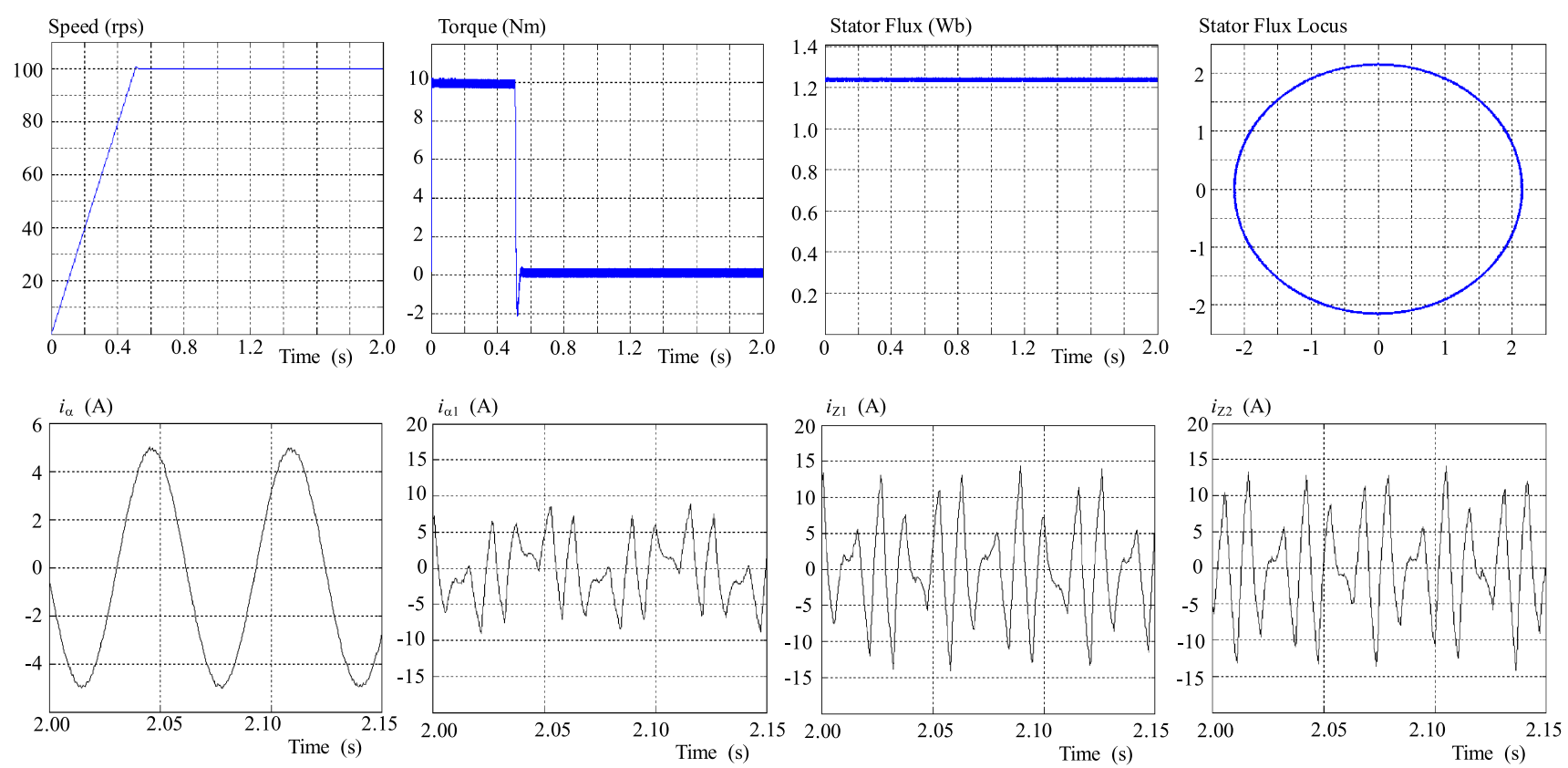

Fig. 8. (a) - Performance of conventional DSSM DTC when $\Omega<\Omega_{\text {nom }} / 2$, (b) - Permanents currents at $T_{r}=10 \mathrm{Nm}$ and $\Omega=$ $100 \operatorname{rps}\left(\Omega<\Omega_{\mathrm{nom}} / 2\right)$

Table 2. The switching states for inverters when $\Omega<\Omega_{\text {nom }} / 2$

\begin{tabular}{cc|cccccccccccc}
\hline$\Phi$ & $\tau$ & $\Theta_{1}$ & $\Theta_{2}$ & $\Theta_{3}$ & $\Theta_{4}$ & $\Theta_{5}$ & $\Theta_{6}$ & $\Theta_{7}$ & $\Theta_{8}$ & $\Theta_{9}$ & $\Theta_{10}$ & $\Theta_{11}$ & $\Theta_{12}$ \\
\hline \multirow{2}{*}{1} & 1 & $u_{3}$ & $u_{4}$ & $u_{5}$ & $u_{6}$ & $u_{7}$ & $u_{8}$ & $u_{9}$ & $u_{10}$ & $u_{11}$ & $u_{12}$ & $u_{1}$ & $u_{2}$ \\
& 0 & $u_{1}$ & $u_{2}$ & $u_{3}$ & $u_{4}$ & $u_{5}$ & $u_{6}$ & $u_{7}$ & $u_{8}$ & $u_{9}$ & $u_{10}$ & $u_{11}$ & $u_{12}$ \\
& -1 & $u_{11}$ & $u_{12}$ & $u_{1}$ & $u_{2}$ & $u_{3}$ & $u_{4}$ & $u_{5}$ & $u_{6}$ & $u_{7}$ & $u_{8}$ & $u_{9}$ & $u_{10}$ \\
\hline \multirow{2}{*}{0} & 1 & $u_{5}$ & $u_{6}$ & $u_{7}$ & $u_{8}$ & $u_{9}$ & $u_{10}$ & $u_{11}$ & $u_{12}$ & $u_{1}$ & $u_{2}$ & $u_{3}$ & $u_{4}$ \\
& 0 & $u_{7}$ & $u_{8}$ & $u_{9}$ & $u_{10}$ & $u_{11}$ & $u_{12}$ & $u_{1}$ & $u_{2}$ & $u_{3}$ & $u_{4}$ & $u_{5}$ & $v_{6}$ \\
& -1 & $u_{9}$ & $u_{10}$ & $u_{11}$ & $u_{12}$ & $u_{1}$ & $u_{2}$ & $u_{3}$ & $u_{4}$ & $u_{5}$ & $u_{6}$ & $u_{7}$ & $u_{8}$ \\
\hline
\end{tabular}

When the speed $\Omega \geq \Omega_{\text {nom }} / 2$ we use Table 1a to select the proper voltage vector for the first star and the Table $1 \mathrm{~b}$ for the second star.

\subsection{Simulations results}

The simulations results in Figs. 8 and 9 shows that basic DTC regulates the speed and stator flux well. We can see that, this control approach ensure good decoupling between stator flux linkage and torque. However, in this approach the phase currents are distorted as consequence a very high currents harmonics $i z_{1}$ and $i z_{2}$ especially when $\Omega \geq \Omega_{\text {nom }} / 2$ where we use medium and large voltages. Figure 10 gives the response of the torque and flux when the stator resistance increases. The obtained result shows that the torque and flux are oscillating and the global system is unstable. To overcome these problems, we propose in the next section a new DSSM-DTC method based on adaptive fuzzy control.

\section{DTC BASED ON ADAPTIVE FUZZY CONTROL}

In this section, our purpose is to synthesis a control laws in order to obtain almost sinusoidal phase currents and keep at a minimum currents harmonics $i z_{1}$ and $i z_{2}$ by using appropriate PWM modulation strategies. The proposed DTC adaptive fuzzy control problem is to force the system (21) to follow a given bounded reference signal, Fig. 11.

Proposition 1. Consider the DSSM plant model (15). Let the ideal control laws be

$$
\begin{aligned}
& v_{x}^{*}=\frac{1}{b_{1}}\left(-f_{1}+\frac{d \phi_{s}^{*}}{d t}+k_{1} e_{1}\right), \\
& v_{y}^{*}=\frac{1}{b_{2}}\left(-f_{2}+\frac{d T_{e}^{*}}{d t}+k_{2} e_{2}\right), \\
& T_{e}^{*}=\frac{1}{b_{3}}\left(-f_{3}+\frac{d \Omega^{*}}{d t}+k_{3} e_{3}\right)
\end{aligned}
$$

where

$$
\begin{gathered}
e_{1}=\phi_{s}^{*}-\phi_{s}, \quad e_{2}=T_{e}^{*}-T_{e}, \quad e_{3}=\Omega^{*}-\Omega, \\
k_{1}, k_{2}, k_{3}>0 .
\end{gathered}
$$

Then, the regulated errors $e_{i}$ are asymptotically stable.

P r o of . Consider the following Lyapunov function

$$
V=\frac{1}{2}\left(e_{1}^{2}+e_{2}^{2}+e_{3}^{2}\right) \text {. }
$$

Its time derivative is expressed by

$$
\dot{V}=\dot{e}_{1} e_{1}+\dot{e}_{2} e_{2}+\dot{e}_{3} e_{3} .
$$

The derivative of the errors (29) becomes:

$$
\begin{aligned}
& \dot{e}_{1}=\frac{\mathrm{d} \phi_{s}^{*}}{\mathrm{~d} t}-f_{1}-b_{1} v_{x}, \\
& \dot{e}_{2}=\frac{\mathrm{d} T_{e}^{*}}{\mathrm{~d} t}-f_{2}-b_{2} v_{y}, \\
& \dot{e}_{3}=\frac{\mathrm{d} \Omega^{*}}{\mathrm{~d} t}-f_{3}-b_{3} T_{e} .
\end{aligned}
$$



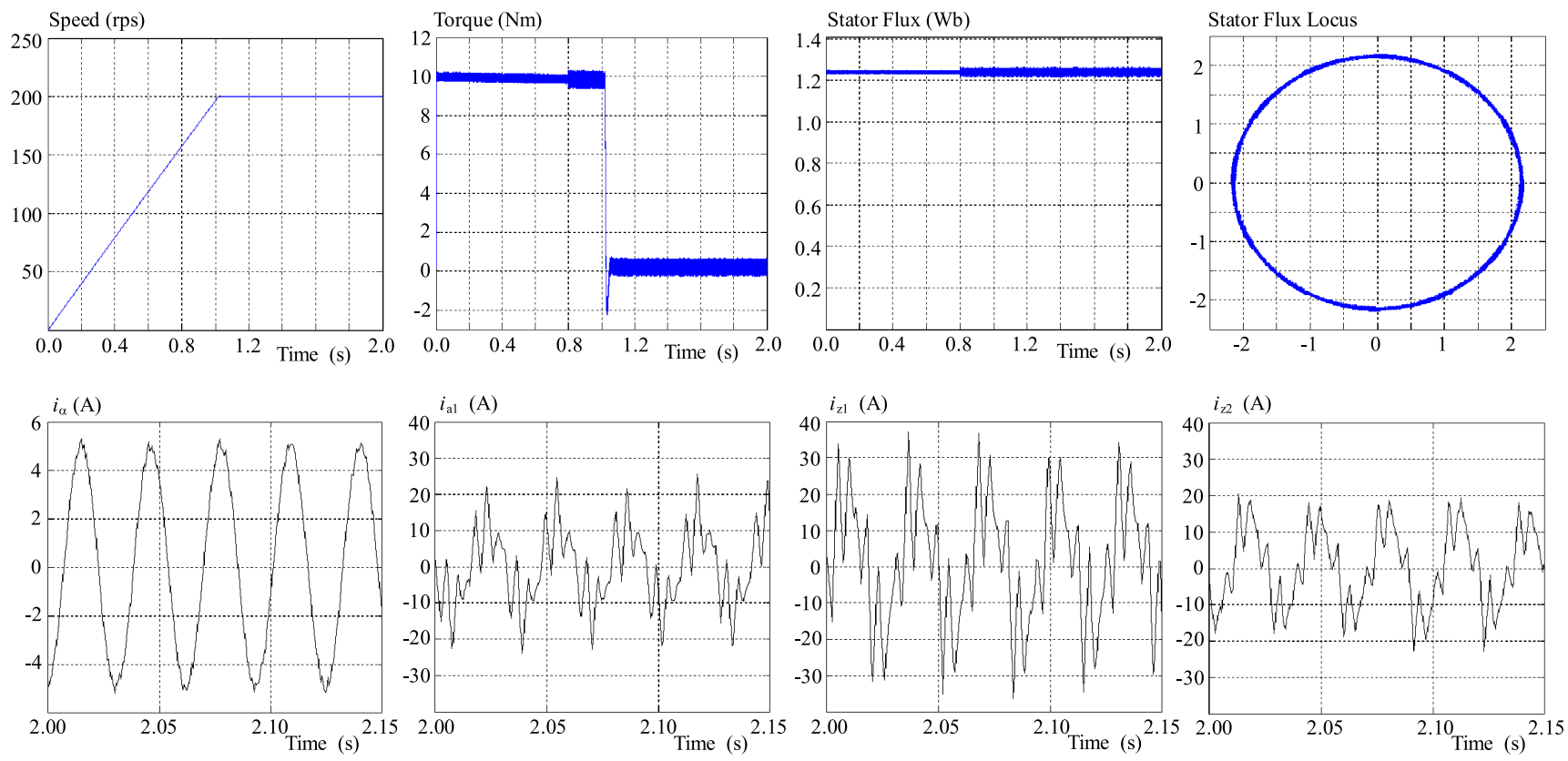

Fig. 9. (a) - Performance of conventional DSSM DTC when $\Omega \geq \Omega_{\text {nom }} / 2$, (b) - Permanents currents at $T_{r}=10 \mathrm{Nm}$ and $\Omega=$ $200 \operatorname{rps}\left(\Omega \geq \Omega_{\mathrm{nom}} / 2\right.$
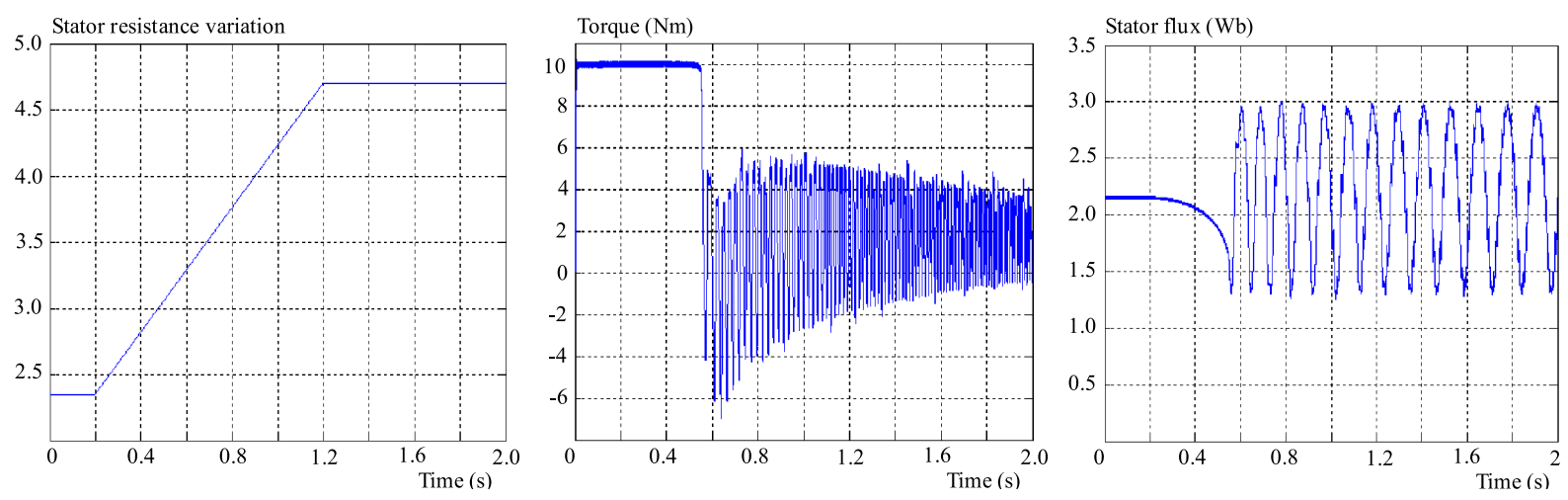

Fig. 10. Performance of conventional DSSM DTC with stator resistance variation

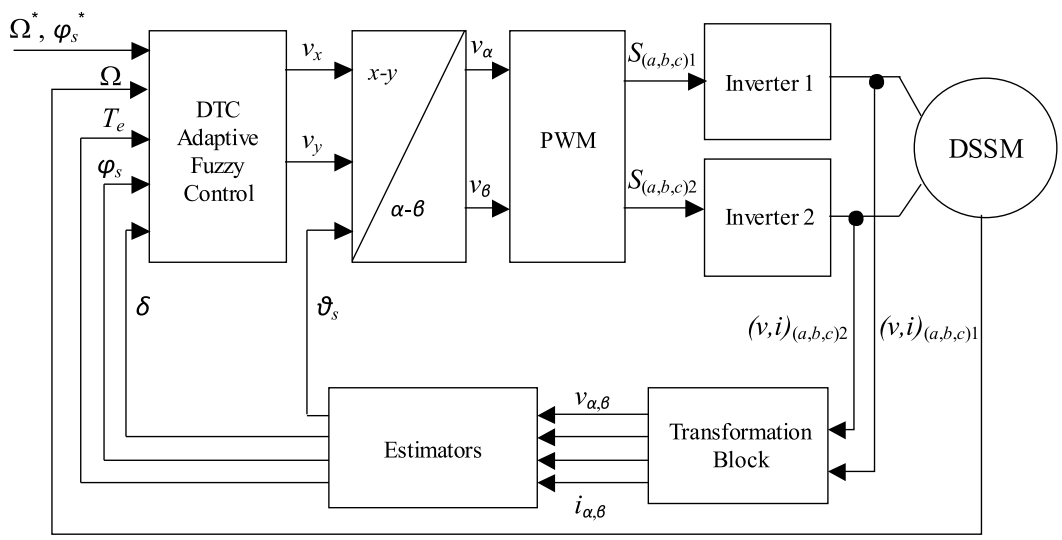

Fig. 11. DTC Adaptive Fuzzy Control scheme for DSSM

Replacing the control low (28) in (32), equation (31) becomes

$$
\dot{V}=-k_{1} e_{1}^{2}-k_{2} e_{2}^{2}-k_{3} e_{3}^{2}<0
$$

Relation (33), means that $e_{1}, e_{2}$ and $e_{3}$ converge at last asymptotically to zero. Therefore the control laws (28) can drive the plant system in the ideal case. 
In practice the nonlinear functions $f_{i}(i=1,2,3)$ involved in the state space model (21) are badly known. The implementation of the control law (28) is inoperative since it requires a precise model. To overcome this problem we use the fuzzy logic system to estimate on-line the nonlinear function given in (28). The ideal control law (28) is ideally rebuilt by a fuzzy logic system such that:

$$
\begin{aligned}
v_{x}^{*} & =W_{1}^{\top}\left(\phi_{s}\right) \theta_{1}+\varepsilon_{1}\left(\phi_{s}\right), \\
v_{y}^{*} & =W_{2}^{\top}\left(T_{e}\right) \theta_{2}+\varepsilon_{2}\left(T_{e}\right), \\
T_{e}^{*} & =W_{3}^{\top}(w) \theta_{3}+\varepsilon_{3}(w)
\end{aligned}
$$

where $W_{i}(\cdot)$ is a basis function [21] and $\theta_{i}$ is vector of optimal parameters, while $\varepsilon_{i}(\cdot)$ is the unavoidable reconstruction error satisfying the condition $[22,23]$

$$
\left|\varepsilon_{1}\left(\phi_{s}\right)\right| \leq \bar{\varepsilon}_{1}, \quad\left|\varepsilon_{2}\left(T_{e}\right)\right| \leq \bar{\varepsilon}_{2}, \quad\left|\varepsilon_{3}(w)\right| \leq \bar{\varepsilon}_{3} .
$$

The ideal control law (34) is estimated by:

$$
\hat{v}_{x}=W_{1}^{\top}\left(\phi_{s}\right) \hat{\theta}_{1}, \quad \hat{v}_{y}=W_{2}^{\top}\left(T_{e}\right) \hat{\theta}_{2}, \quad \hat{T}_{e}=W_{3}^{\top}(\Omega) \hat{\theta}_{3}
$$

Where $\hat{\theta}_{i}$, the estimate of the best parameters $\theta_{i}$.

Subtracting (36) from (34), we obtain the estimation errors

$$
\begin{aligned}
v_{x}^{*}-\hat{v}_{x} & =W_{1}^{\top}\left(\phi_{s}\right) \tilde{\theta}_{1}+\varepsilon_{1}\left(\phi_{s}\right), \\
v_{y}^{*}-\hat{v}_{y} & =W_{2}^{\top}\left(T_{e}\right) \tilde{\theta}_{2}+\varepsilon_{2}\left(T_{e}\right), \\
T_{e}^{*}-\hat{T}_{e} & =W_{3}^{\top}(w) \tilde{\theta}_{3}+\varepsilon_{3}(w)
\end{aligned}
$$

where $\tilde{\theta}_{i}=\theta_{i}-\hat{\theta}_{i}$ is vector parametric error.

Proposition 2. Consider the following control laws:

$$
\hat{v}_{x}^{*}=\hat{v}_{x}+v_{x a}, \quad \hat{v}_{y}^{*}=\hat{v}_{y}+v_{y a}, \quad \hat{T}_{e}^{*}=\hat{T}_{e}+T_{e a}
$$

with

$$
v_{x a}=\hat{\bar{\varepsilon}}_{1} \operatorname{sign}\left(e_{1}\right), v_{y a}=\hat{\bar{\varepsilon}}_{2} \operatorname{sign}\left(e_{2}\right), T_{e a}=\hat{\bar{\varepsilon}}_{3} \operatorname{sign}\left(e_{3}\right)
$$

where $\hat{\bar{\varepsilon}}_{i}$ and $\hat{\theta}_{i}$ are updated under the laws

$$
\dot{\overline{\hat{\varepsilon}}}_{1}=\eta_{1}\left|e_{1}\right|, \quad \dot{\bar{\varepsilon}}_{2}=\eta_{2}\left|e_{2}\right|, \quad \dot{\bar{\varepsilon}}_{3}=\eta_{3}\left|e_{3}\right|,
$$

$\dot{\hat{\theta}}_{1}=\gamma_{1} W_{1}\left(\phi_{s}\right) e_{1}, \dot{\hat{\theta}}_{2}=\gamma_{2} W_{2}^{\top}\left(T_{e}\right) e_{2}, \dot{\hat{\theta}}_{3}=\gamma_{3} W_{3}^{\top}(\Omega) e_{3}$

where $\eta_{i}$ and $\gamma_{i}$ are positives constants.

Then, the tracking errors $e_{i}$ converge asymptotic toward zero and the parameters are bounded.

P r o of . Let us choose the Lyapunov function

$$
V=V_{1}+V_{2}+V_{3}
$$

with

$$
\begin{aligned}
& V_{1}=\frac{1}{2 b_{1}} e_{1}^{2}+\frac{1}{2 \gamma_{1}} \tilde{\theta}_{1}^{\top} \tilde{\theta}_{1}+\frac{1}{2 \eta_{1}} \tilde{\varepsilon}_{1}^{2}, \\
& V_{2}=\frac{1}{2 b_{2}} e_{2}^{2}+\frac{1}{2 \gamma_{2}} \tilde{\theta}_{2}^{\top} \tilde{\theta}_{2}+\frac{1}{2 \eta_{2}} \tilde{\bar{\varepsilon}}_{2}^{2}, \\
& V_{3}=\frac{1}{2 b_{3}} e_{3}^{2}+\frac{1}{2 \gamma_{3}} \tilde{\theta}_{3}^{\top} \tilde{\theta}_{3}+\frac{1}{2 \eta_{3}} \tilde{\tilde{\varepsilon}}_{3}^{2}
\end{aligned}
$$

where $\tilde{\bar{\varepsilon}}_{i}=\bar{\varepsilon}_{i}-\hat{\bar{\varepsilon}}_{i}$. These functions are globally positive. Its time derivates are given by

$$
\begin{aligned}
& \dot{V}_{1}=\frac{1}{b_{1}} e_{1} \dot{e}_{1}-\frac{1}{\gamma_{1}} \tilde{\theta}_{1}^{\top} \dot{\hat{\theta}}_{1}-\frac{1}{\eta_{1}} \tilde{\bar{\varepsilon}}_{1} \dot{\bar{\varepsilon}}_{1}, \\
& \dot{V}_{2}=\frac{1}{b_{2}} e_{2} \dot{e}_{2}-\frac{1}{\gamma_{2}} \tilde{\theta}_{2}^{\top} \dot{\hat{\theta}}_{2}-\frac{1}{\eta_{2}} \tilde{\bar{\varepsilon}}_{2} \dot{\bar{\varepsilon}}_{2}, \\
& \dot{V}_{3}=\frac{1}{b_{3}} e_{3} \dot{e}_{3}-\frac{1}{\gamma_{3}} \tilde{\theta}_{3}^{\top} \dot{\hat{\theta}}_{3}-\frac{1}{\eta_{3}} \tilde{\bar{\varepsilon}}_{3} \dot{\bar{\varepsilon}}_{3}
\end{aligned}
$$

where the time derivates of the tracking error dynamic are

$$
\begin{aligned}
& \dot{e}_{1}=-k_{1} e_{1}+b_{1}\left(W_{1}^{\top}\left(\phi_{s}\right) \tilde{\theta}_{1}+\varepsilon_{1}\left(\phi_{s}\right)-v_{x a}\right), \\
& \dot{e}_{2}=-k_{2} e_{2}+b_{2}\left(W_{2}^{\top}\left(T_{e}\right) \tilde{\theta}_{2}+\varepsilon_{2}\left(T_{e}\right)-v_{y a}\right), \\
& \dot{e}_{3}=-k_{3} e_{3}+b_{3}\left(W_{3}^{\top}(w) \tilde{\theta}_{3}+\varepsilon_{3}(w)-T_{e a}\right) .
\end{aligned}
$$

Substituting (35) and (45) in (44), it results

$$
\begin{aligned}
& \dot{V}_{1}=-\frac{k_{1}}{b_{1}} e_{1}^{2}+\varepsilon_{1}\left(\phi_{s}\right) e_{1}-v_{x a} e_{1}-\frac{1}{\eta_{1}} \tilde{\bar{\varepsilon}}_{1} \dot{\bar{\varepsilon}}_{1}, \\
& \dot{V}_{2}=-\frac{k_{2}}{b_{2}} e_{2}^{2}+\varepsilon_{2}\left(T_{e}\right) e_{2}-v_{y a} e_{2}-\frac{1}{\eta_{2}} \tilde{\bar{\varepsilon}}_{2} \dot{\bar{\varepsilon}}_{2}, \\
& \dot{V}_{3}=-\frac{k_{3}}{b_{3}} e_{3}^{2}+\varepsilon_{3}(w) e_{3}-T_{e a} e_{3}-\frac{1}{\eta_{3}} \tilde{\bar{\varepsilon}}_{3} \dot{\bar{\varepsilon}}_{3} .
\end{aligned}
$$

Introducing (40) into (46), we obtain

$$
\begin{aligned}
& \dot{V}_{1}=-\frac{k_{1}}{b_{1}} e_{1}^{2}+\varepsilon_{1}\left(\phi_{s}\right) e_{1}-\hat{\bar{\varepsilon}}_{1}\left|e_{1}\right|-\frac{1}{\eta_{1}} \tilde{\bar{\varepsilon}}_{1} \dot{\bar{\varepsilon}}_{1}, \\
& \dot{V}_{2}=-\frac{k_{2}}{b_{2}} e_{2}^{2}+\varepsilon_{2}\left(T_{e}\right) e_{2}-\hat{\bar{\varepsilon}}_{2}\left|e_{2}\right|-\frac{1}{\eta_{2}} \tilde{\bar{\varepsilon}}_{2} \dot{\bar{\varepsilon}}_{2}, \\
& \dot{V}_{3}=-\frac{k_{3}}{b_{3}} e_{3}^{2}+\varepsilon_{3}(w) e_{3}-\hat{\bar{\varepsilon}}_{3}\left|e_{3}\right|-\frac{1}{\eta_{3}} \tilde{\bar{\varepsilon}}_{3} \dot{\bar{\varepsilon}}_{3} .
\end{aligned}
$$

Use the condition (35) yields

$$
\begin{aligned}
& \dot{V}_{1} \leq-\frac{k_{1}}{b_{1}} e_{1}^{2}+\tilde{\bar{\varepsilon}}_{1}\left|e_{1}\right|-\frac{1}{\eta_{1}} \tilde{\bar{\varepsilon}}_{1} \dot{\overline{\bar{\varepsilon}}}_{1}, \\
& \dot{V}_{2} \leq-\frac{k_{2}}{b_{2}} e_{2}^{2}+\tilde{\bar{\varepsilon}}_{2}\left|e_{2}\right|-\frac{1}{\eta_{2}} \tilde{\bar{\varepsilon}}_{2} \dot{\overline{\bar{\varepsilon}}}_{2}, \\
& \dot{V}_{3} \leq-\frac{k_{3}}{b_{3}} e_{3}^{2}+\tilde{\bar{\varepsilon}}_{3}\left|e_{3}\right|-\frac{1}{\eta_{3}} \tilde{\bar{\varepsilon}}_{3} \dot{\overline{\bar{\varepsilon}}}_{3} .
\end{aligned}
$$

By exploiting the update law (40), relation (48) becomes:

$$
\dot{V}_{1} \leq-\frac{k_{1}}{b_{1}} e_{1}^{2}, \quad \dot{V}_{2} \leq-\frac{k_{2}}{b_{2}} e_{2}^{2}, \quad \dot{V}_{3} \leq-\frac{k_{3}}{b_{3}} e_{3}^{2} .
$$

Finally, we can write

$$
V_{1} \leq-\frac{k_{1}}{b_{1}} e_{1}^{2}-\frac{k_{2}}{b_{2}} e_{2}^{2}-\frac{k_{3}}{b_{3}} e_{3}^{2} \leq 0 .
$$

Hence using the Lyapunov theorem, we conclude that the control law (38) and the parameters adaptation law (40) and (41) ensure the asymptotic convergence of the tracking error $e_{i}$ toward zero and the boundedness of the parameters. 

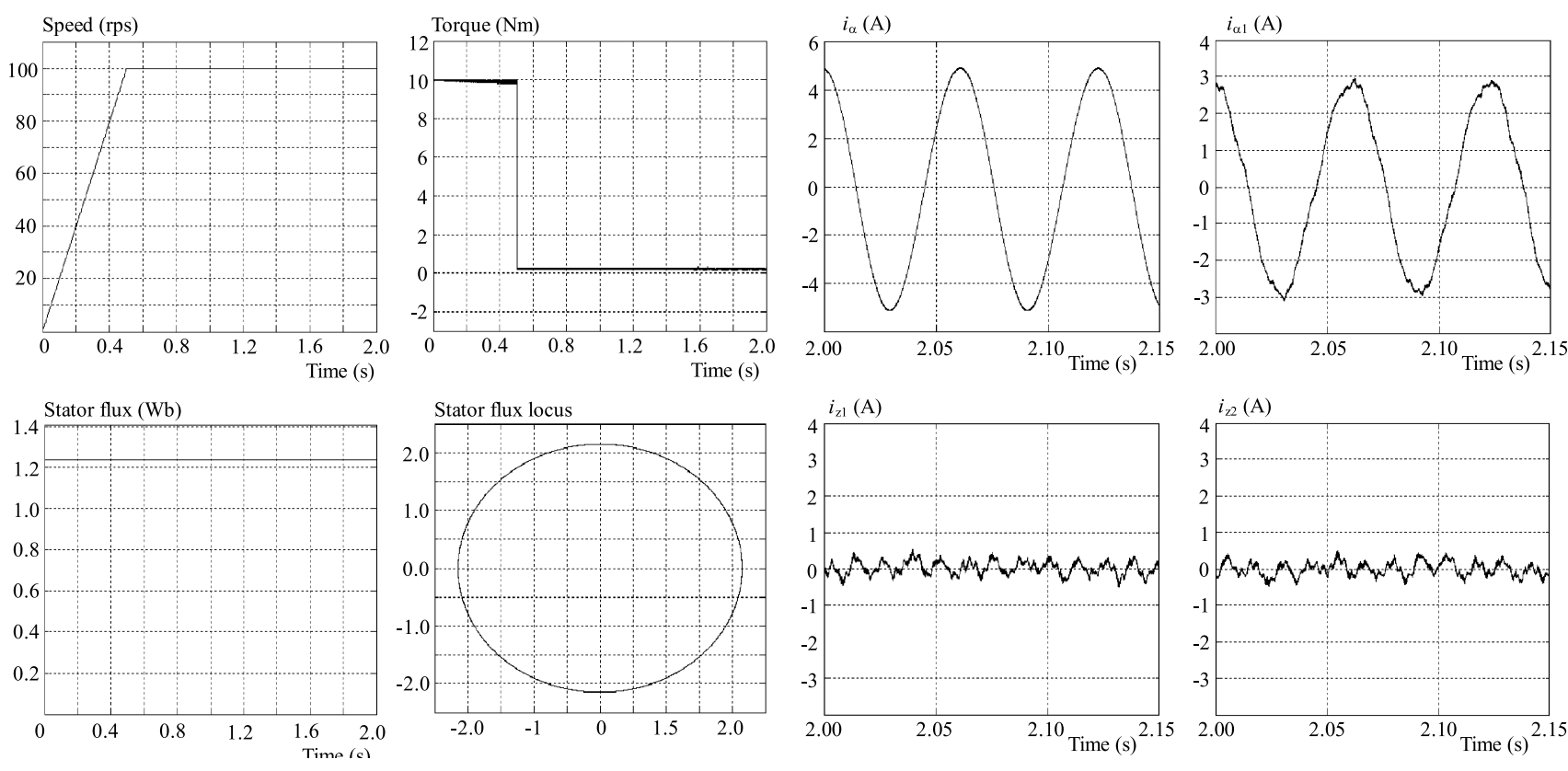

Fig. 12. (a) - Performance of DTC adaptive fuzzy control of DSSM when $\Omega<\Omega_{\text {nom }} / 2$, (b) - Permanents currents at $T_{r}=10 \mathrm{Nm}$ and $\Omega=100 \operatorname{rps}\left(\Omega<\Omega_{\mathrm{nom}} / 2\right.$
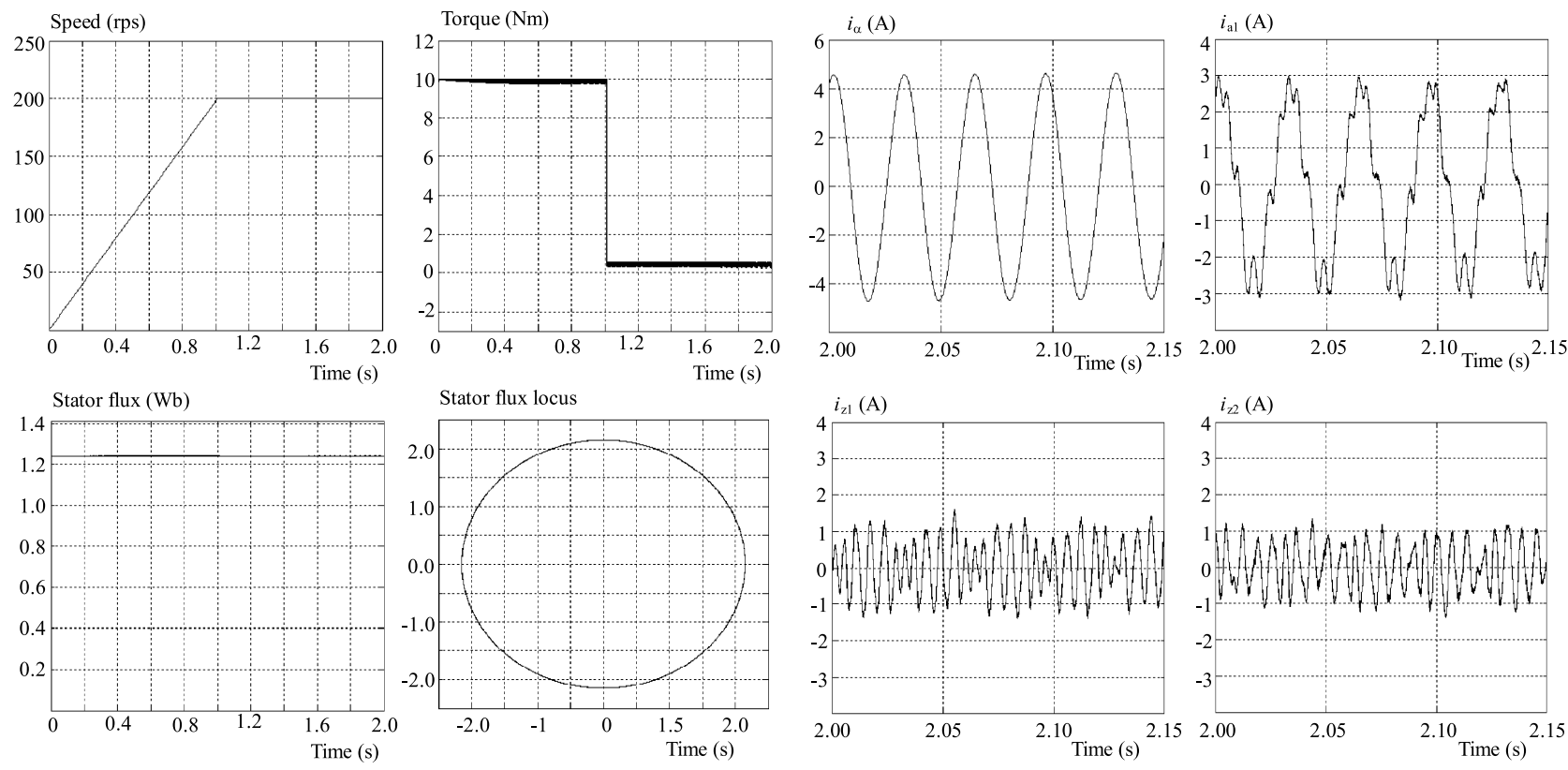

Fig. 13. (a) - Performance of DTC adaptive fuzzy control of DSSM when $\Omega \geq \Omega_{\text {nom }} / 2$, (b) - Permanents currents at $T_{r}=10 \mathrm{Nm}$ and $\Omega=200 \operatorname{rps}\left(\Omega \geq \Omega_{\mathrm{nom}} / 2\right.$

\subsection{Simulations results}

Figures 12 and 13 give the performance of DTC adaptive fuzzy control of DSSM fed by two tree level inverter PWM respectively when $\Omega<\Omega_{\text {nom }} / 2$ and $\Omega \geq \Omega_{\text {nom }} / 2$. It appears that, the speed and stator flux follows their reference, the torque and the flux are decoupled and the harmonic currents are greatly reduced. Figure 14 gives the response of the torque and flux when the stator resistance increases. The obtained result shows that the torque and flux follows their reference and the system is stable.

\section{CONCLUSION}

In this paper, a new direct torque control method of DSSM is presented and its merits over the conventional DTC approach are confirmed by the simulation results. This new direct torque control uses the adaptive controller based on fuzzy systems. The proposed method uses the Sugeno-Takagi fuzzy system as a universal approximator of continuous nonlinear functions. The adaptive control law is established based on the Lyapunov method. So, the output convergence, the boundedness of 

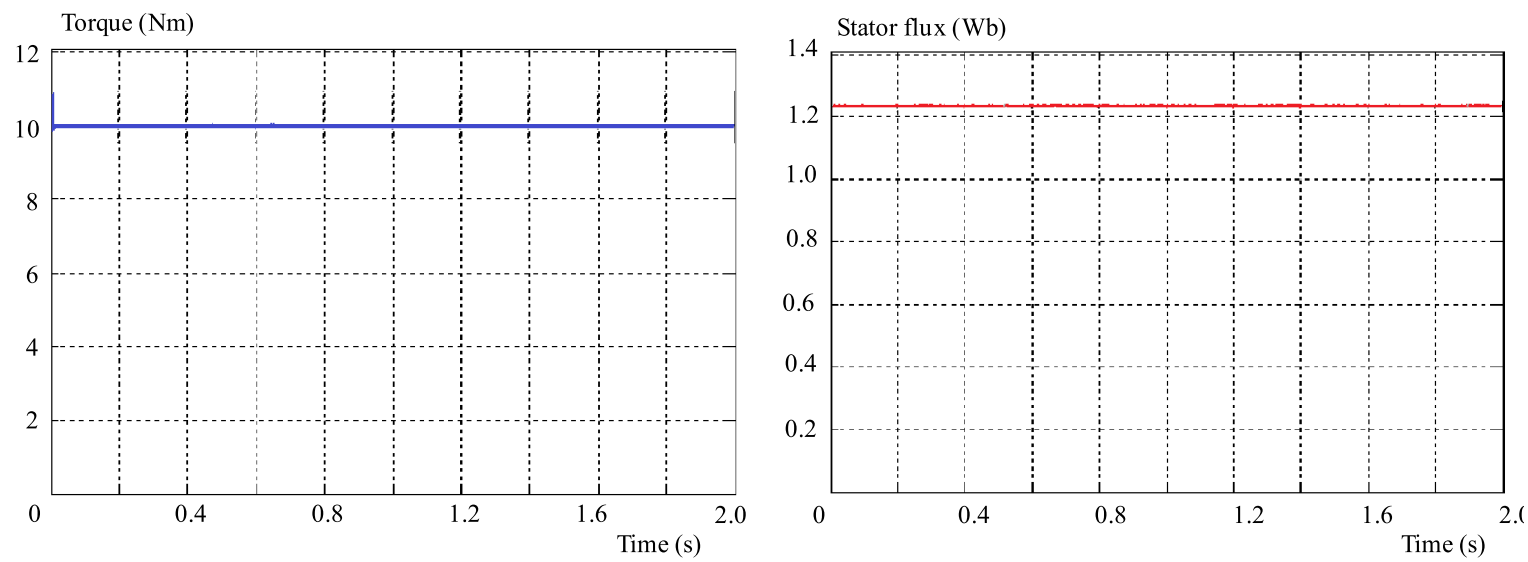

Fig. 14. Performance of DTC adaptive fuzzy control of DSSM with stator resistance variation

the parameters and the states are derived. Moreover, the fuzzy adaptive law incorporates a compensatory sliding term, which compensates for effects of the unavoidable reconstruction errors. The features of the proposed direct torque control method include 1) providing constant inverter switching frequency, 2) significantly reducing the torque ripple and harmonic currents on the $z_{1}-z_{2}$ plane, 3) good robustness to the variation of the stator resistance.

\section{Appendix 1. List of principal symbols}

$i_{a 1}, i_{b 1}, i_{c 1}:$ stator current $a, b, c$ phase of the first winding,

$i_{a 2}, i_{b 2}, i_{c 2}:$ stator current $a, b, c$ phase of the second winding,

$i_{\alpha}, i_{\beta} \quad:$ stator current $\alpha-\beta$ axis,

$i_{x}, i_{y} \quad:$ stator current $x-y$ axis,

$i_{s} \quad:$ stator current vector,

$v_{a 1}, v_{b 1}, v_{c 1}$ : simple voltage of stator three phase first winding,

$v_{a 2}, v_{b 2}, v_{c 2}$ : simple voltage of stator three phase second winding,

$v_{s} \quad:$ stator voltage vector,

$v_{d}, v_{q} \quad:$ stator voltages $d-q$ axis,

$v_{\alpha}, v_{\beta} \quad:$ stator voltages $\alpha-\beta$ axis,

$v_{x}, v_{y} \quad:$ stator voltages $x-y$ axis,

$L_{d}, L_{q} \quad: d-q$ inductances,

$\mathbf{L}_{s s} \quad$ : stator inductance matrix,

$\mathbf{M}_{s r} \quad$ : stator-rotor mutual inductance matrix,

$\left.\begin{array}{lllllll}\mathbf{R}_{s} & : \operatorname{diag}\left(R_{s}\right. & R_{s} & R_{s} & R_{s} & R_{s} & R_{s}\end{array}\right)$,

$R_{s} \quad:$ : stator resistance,

$R_{f} \quad$ : rotor resistance,

$T_{e}, T_{e}^{*} \quad:$ electromagnetic torque, reference torque,

$T_{r} \quad$ : load torque,

$\varphi_{s}, \varphi_{s}^{*} \quad:$ stator flux vector, reference flux vector,

$\varphi_{d}, \varphi_{q} \quad:$ stator flux $d-q$ axis,

$\varphi_{\alpha}, \varphi_{\beta} \quad:$ stator flux $\alpha-\beta$ axis,

$\varphi_{x}, \varphi_{y} \quad:$ stator flux $x-y$ axis,

$\Omega \quad$ : rotating speed of rotor flux linkage,

$w \quad$ : rotating speed of rotor flux linkage,

$w_{s} \quad$ : rotating speed of stator flux linkage,

$\Phi \quad$ : output of the flux hysteresis comparator, $\tau \quad$ : output of the torque hysteresis comparator,

$\delta \quad:$ angle between rotor and stator flux linkage,

$\theta_{r}, \theta_{s} \quad$ : angle of rotor flux linkage, angle of stator flux linkage,

$\Theta_{i} \quad$ : the region numbers for the stator linkage positions,

$E_{T}, E_{\varphi} \quad$ : torque error, flux error,

$J \quad:$ moment of inertia,

$f_{r} \quad:$ friction coefficient,

$P \quad$ : number of pole pairs.

\section{Appendix 2. DSSM parameters}

$P_{n}=5 \mathrm{~kW}, \quad U_{c}=232 \mathrm{~V}, \quad i_{f}=1 \mathrm{~A}, \quad R_{s}=2.35 \Omega$,

$R_{f}=30.3 \Omega, L_{d}=0.3811 \mathrm{H}, L_{f}=15 \mathrm{H}, M_{d}=2.146 \mathrm{H}$,

$J=0.05 \mathrm{Nms}^{2} / \mathrm{rd}, \quad f_{r}=0.001 \mathrm{Nms} / \mathrm{rd}, P=1$.

\section{REFERENCES}

[1] WERREN, L.: Synchronous Machine with 2 Three Phase Winding, Spatially Displaced by 30EL. Commutation Reactance and Model for Converter-Performance Simulation, ICEM September 1984, vol. 2, Lausanne (Switzerland), pp. 781-784.

[2] SCHIFERL, R. F.-ONG, C. M. : Six Phase Synchronous Machine with AC and DC Stator Connections, IEEE Trans. on Power Apparatus and Systems PAS-102 No. 8 (Aug 1983).

[3] MOUBAYED, N.-MEIBODY-TABAR, F.-DAVAT, B. : Alimentation par deux onduleurs de tension dune machine synchrone double étoile, Revue Internationale de Génie Electrique (RIGE) 1 No. 4 (1998), 457-470.

[4] BENKHORIS, M. F.-MERABTENE, M.-MEIBODY-TABAR, F.-DAVAT, B.-SEMAIL, E. : Approches de modélisation de la machine synchrone double étoile alimentée par des onduleurs de tension en vue de la commande, RIGE 6 No. 5-6 (2003), 579-608.

[5] BUJA, G. S.-KAZMIERKOWSKI, M. P. : Direct Torque Control of PWM Inverter-Fed AC Motors - A Survey, IEEE Transactions on Industrial Electronics 51 No. 4 (Aug 2004), 744-756.

[6] THON, C. L.-IDRIS, N. N. R.-YATIM, A. H. M.: Constant and High Switching Frequency Torque Controller for DTC Drives, IEEE Power Electronics Letters 3 No. 2 (June 2005), 76-80.

[7] BUJA, G.-CASADEI, D.-SERRA, G. : Direct Stator Flux and Torque Control of an Induction Motor: Theoretical Analysis and Experimental Results, in Proceedings of the IECON 98, vol. 1, 1998, pp. 150-164. 
[8] TANG, L.-ZHONG, L.-RAHMAN, M. F.-HU, Y.: A Novel Direct Torque Controlled Interior Permanent Magnet Synchronous Machine Drive with Low Ripple in Flux and Torque and Fixed Switching Frequency, IEEE Transactions on Power Electronics 19 No. 2 (March 2004), 346-354.

[9] LASCU, C.-TRZYNADLOWSKI, A. M. : Combining the Principles of Sliding Mode, Direct Torque Control and SpaceVector Modulation in a High-Performance Sensorless AC Drive, IEEE Transactions on Industry Applications 40 No. 1 (Jan/Feb 2004), 170-177.

[10] BELlOMOA, D.-NASOB, D.-BABUSKA, R.: Adaptive Fuzzy Control of a Non-Linear Servo-Drive, Elsevier Engineering Applications of Artificial Intelligence vol 21 (2008), 846-857.

[11] TLEMÇANI, A.-CHEKIREB, H.-BOUCHERIT, M. S.DJEMAI, M.: Decentralized Direct Adaptive Fuzzy Control of Permanent Magnet Synchronous Motor, The Mediterranean Journal of Measurement and Control 4 No. 1 (2008), 33-43.

[12] TLEMÇANI, A.-CHEKIREB, H.-BOUCHERIT, M. S. : A new Robust Adaptive Control of a Class of MIMO Nonlinear Systems with Fuzzy Approximators, Archives of Control Sciences 16 No. 3 (2006), 247-264.

[13] TAKAGI, T.-SUGENO, M. : Fuzzy Identification of Systems and its Applications to Modeling and Control, IEEE Trans. Systems, Man and Cybernetics 15 No. 1 (1985), 116-132.

[14] WANG, L. X. : Design and Analysis of Fuzzy Identifiers of Nonlinear Dynamics Systems, IEEE Trans. on Automatic Control 40 No. 1 (Jan 1995), 11-23.

[15] MERABTEnE, M.: Modelisation dynamique et commande d'une machine synchrone double étoile, alimentée par des onduleurs MLI fonctionnement en mode normal et dégrade, Thèse de doctorat de luniversité de Nantes, July 2005.

[16] ZONG, L.-RAHMAN, M. F.-HU, W. Y.-LIM, K. W. : A Direct Torque Controller for Permanent Magnet Synchronous Motor Drives, IEEE Transactions on Energy Conversion 14 No. 3 (Sep 1999).

[17] ZONG, L.-RAHMAN, M. F.-HU, W. Y.-LIM, K. W. : Analysis of Direct Torque Control in Permanent Magnet Synchronous Motor Drives, IEEE Transactions Power Electronics 12 No. 3 (1997), 528-536.

[18] ZHAO, Y.-LIPO, T. A.: Space Vector PMW Control of Dual Three-Phase Induction Machine using Vector Space Decomposition, IEEE Transactions on Industry Applications 31 No. 5 (Sep/Oct 1995), 1100-1109.

[19] BOUDANA, D.-NEZLI, L.-MARMOUDI, M. O.-TLEMÇANI, A.-DJEMAI, M.: DTC Based on Fuzzy Logic Control of a Double Star Synchronous Machine Drive, Nonlinear Dynamics and Systems Theory 3 (July 2008), 269-286.

[20] BOUDANA, D.: Sur la commande DTC basée sur les techniques de contrôle robuste de la machine synchrone à double étoile alimentée par convertisseurs multiniveaux, Thèse de doctorat de lEcole Nationale Supŕieure Polytechnique, Algeria, Oct 2009

[21] MENDEL, J. M.: Fuzzy Systems for Engineering, A tutorial, Proc. IEEE 83 (1995), 347-377.
[22] WANG, L. X.-MENDEL, J. M.: Back-Propagation Fuzzy Systems as Nonlinear Dynamic System Identifiers, Proc. IEEE Int. Conf. on Fuzzy Systems, 1992, pp. 1409-1418.

[23] WANG, L.: Design and Analysis of Fuzzy Identifiers of Nonlinear Dynamic Systems, IEEE Trans. on Automatic Control 40 No. 1 (1995), 11-23.

Received 10 July 2010

Djamel Boudana was born in 1971 in Algiers, Algeria. He received the Engineer degree in Electrotechnics, and magister degree in Electrical engineering, from USTHB Algiers, Algeria, in 1995, 1999 respectively. He received the doctor degree in electrical engineering from the National Polytechnic School of Algiers (ENP), Algeria, in 2009. Since 2001 he has help teaching and research positions in the Department of Electrical Engineering, UYFM, where he is currently assistant professor. His research interests are in electrical drives.

Lazhari Nezli was born in Algeria in 1957. He received the electrical engineering degree, the magister degree and the doctor degree from the national polytechnic school of Algiers (Algeria ) in 1982, 1986 and 2006 respectively. Since 1987, he holds teaching and research positions at the department of electrical engineering ENP, where he is currently assistant professor. His areas of research interest are modeling and electrical machines drives.

Abdelhalim Tlemçani received his engineering degree and MSc in power electronics from the National Polytechnic School of Algiers (ENP), Algeria, in 1997 and 1999, respectively. He gained the doctorate in electrical engineering from ENP in 2007. Since 2002 he has help teaching and research positions in the Department of Electrical Engineering, UYFM, where he is currently associate professor. He is director of Control and Power Electronics Research Group. His research interests are in the field of power electronics, electrical drives, robust and nonlinear control and fuzzy systems.

Mohand Oulhadj Mahmoudi was born in Algiers (Algeria) in 1956. He received the Engineer diploma, the magister degree and the doctor degree in Electrical Engineering from the National Polytechnic School of Algiers (Algeria) in 1982, 1986 and 1999 respectively. Since 1986, he holds teaching and research position at the electrical engineering department where he is currently full professor. His areas of research interest are in Power Electronics and Electrical Machines Drive.

Mohamed Tadjine was born in Algiers (Algeria) in 1966. He received the DEA degree and the doctor degree in Automatic Control from the National Polytechnic Institute of Grenoble (France) in 1991,1994 respectively. Since 1997, he holds teaching and research position at the electrical engineering department where he is currently full professor. His areas of research interest are in robust and nonlinear control, observers, FDI and electrical machines drive. 